\title{
Crack Growth Behavior through Wall Pipes under Impact Load and Hygrothremal Environment
}

\author{
Ali Jamal Khaled* Ahmed Abdul Hussain** \\ ***Department of Mechanical Engineering/College of Engineering/University of Baghdad \\ *Email: engalijama193@gmail.com \\ **Email: ahmedrobot65@yahoo.com
}

(Received 12 February 2018; accepted 14 May 2018)

https://doi.org/10.22153/kej.2018.05.001

\begin{abstract}
This research concerns study the crack growth in the wall of pipes made of low carbon steel under the impact load and using the effect of hygrothermal (rate of moisture $50 \%$ and $50^{\circ} \mathrm{C}$ temperature). The environmental conditions were controlled using high accuracy digital control with sensors. The pipe have a crack already. The test was performed and on two type of specimens, one have length of $100 \mathrm{~cm}$ and other have length $50 \mathrm{~cm}$. The results were, when the humidity was applied to the pipe, the crack would enhance to growth (i.e. the number of cycles needed to growth the crack will reduce). In addition, when the temperature was increase the number of cycles needed to growth the crack are reduced because the effect of heat on the mechanical properties of the material. In addition, when the test performed on the specimens of length $50 \mathrm{~cm}$ the number of cycles needed to growth the crack is increase because the effect of bending stress on the pipes.
\end{abstract}

Keywords: Cracks, crack initiation, crack growth, hygyothermal, pipes failure.

\section{Introduction}

Cracks define as a discontinuity or break which occur in solid (rigid) body and it branded by having an initiation point and by growing from this point to finite size with time. Either leading or not to the separation the original body in two or more parts. Crack growth depended on the loading conditions and environmental conditions. Loading conditions presents the type of load such as static load, dynamic load, load controlled, grip controlled. While Environmental conditions like temperature and corrosive atmosphere influence crack growth. [1]

There are three types of cracks in pipe happen due to several causes associated with their types; first the form of a crack, second its dimension and its function. [2]

1. Longitudinal cracks

2. Lateral cracks

3. Cracks origination at a point

\section{The Behavior of Cracks}

The behavior of fatigue cracks differs from that of long cracks because of larger sensitivity to the microstructure. A greater size of the plastic zone fit to the crack length, and a minimum fit to crack finish. Advanced have been made in the understanding of the fatigue crack growth process of cracks, and this understanding has been employed in the advance of analytical treatments of short fatigue crack growth. The study of fatigue crack growth behavior is one of the more active areas of research in the field of fatigue. Such cracks are interest not only because their growth can inhabit an important portion of the fatigue life time but also because they can grow at amount much higher or lower than might be expected on the basis on long crack behavior. There are four kinds of cracks fatigue [3]

1. Mechanically cracks (the crack length is less than plastic zone size) 
2. Micro structurally (the crack length is less than a critical microstructural)

3. Physically (the crack length is less than at which crack closure if fully developed usually less than $1 \mathrm{~mm}$ in length)

4. Chemically (the crack length may be up to 10 $\mathrm{mm})$

\section{Governing Differential Equations}

Paris proposed the following equation for the correct crack propagation law

$\frac{d a}{d N}=C(\Delta k)^{m}$

Where $C$ and $m$ are constant and they depended on the material that be used.

This equation seemed to have good correlation with the test data. However, if comparisons are made with the large range of data, such as a higher load ratios and crack growth rates, the correlations is not good. In fact, equation (1) does not seem to be complete. Two effect occur which are not taken into account. One of this variation in the crack growth rate owing to the load ratio, $R$. the other is the instability of the crack growth when the value of the maximum stress intensity factor approaches to the fracture toughness of the material, $\mathbf{K}_{\mathrm{c},}$ [4]

\section{Criteria of Crack Growth}

Theoretical and experimental work contains different criteria like crack position, shape of crack, length of crack and crack angle. Moreover, approximation for the study of the crack growing path. Several of this study are created on the stress analysis of the crack tip region. Erdogan and Sih first examined the angled crack. They suggested the MTS criteria basing the stress domain present just before the start of break for guess of the orientation of the initial crack growth. Conferring to the MTS criteria the crack extend in the radial way agreeing to the tangential stress and the crack growth occur then this maximum arrive a ticklish value. Erdogan and Sih's study was created on the presentation of the crack tip stress region in expressions of stress function resulting by Williams [5].

$\emptyset=r^{3 / 2} f_{1}(\theta)+r^{2} f_{2}(\theta)+r^{5 / 2} f_{3}(\theta)$

For the first term the stress are representation by:

$\sigma_{\theta}=\frac{1}{\sqrt[2]{2 \pi r}} \cos \frac{1}{2} \theta\left(k_{1} \cos ^{2} \frac{\theta}{2}-k_{2} \sin \theta\right) \ldots$
$\tau_{r \theta}=\frac{1}{2 \sqrt{2 \pi r}} \cos \frac{1}{2} \theta\left[k_{1} \sin \theta+k_{2}(3 \cos \theta-1)\right.$
Erdogan and Sih suggested that the direction of crack growth is given by the condition:

$\frac{d k_{\theta}}{d \theta}=0$

Where:

$k_{\theta}=\cos ^{2} \frac{\theta}{2}\left(k_{1} \cos \frac{\theta}{2}-3 k_{2} \sin \frac{\theta}{2}\right)$

$\cos \frac{\theta}{2}\left[k_{I} \sin \theta+k_{I I}(3 \cos \theta-1)\right]=0$

A better covenant among the theoretical and experimental has been gotten by a personification of the stress region using the first two relations of the Eigen function, equation (2). In addition, by using a lesser but finite radius to detect the maximum assessment of $\sigma_{\theta}$ and this was exposed by Williams and Ewing. The elastic strain energy $d W$ kept in parallel pipe of volume $d V$ in the dominate Sih expresses region of the strained plate: $\frac{d W}{d V}=\frac{1+v}{4 E}\left[k_{1,2}\left(\sigma_{x}+\sigma_{y}\right)^{2}+\left(\sigma_{x}-\sigma_{y}\right)^{2}+\right.$ $\left.4\left(\tau_{x y}\right)^{2}\right]$

$k_{1}=\frac{1-v}{1+v} \quad$ For plane stress

$k_{2}=1-2 v$ For plane strain

Papadopoulos used the elastic strain energy approached to suggest a standard of break, which takings into account the third stress constant Det. $\left(\sigma_{\mathrm{ijj}}\right)$

$\operatorname{Det} .\left(\sigma_{i j}\right)=\left|\begin{array}{cc}\sigma_{x} & \sigma_{x y} \\ \sigma_{y x} & \sigma_{y}\end{array}\right|$

Where:

$\sigma_{y x}=\sigma_{x y}$

Conferring to the Det. - criteria the position of crack growth for the mixed mode loading is specified from the state that the determinate of the stress tensor necessity take a maximum rate. In a polar coordinate system, the relations express these conditions mathematically:

$\left.\frac{\partial \operatorname{Det} .\left(\sigma_{i j}\right)}{\partial \theta}\right|_{\theta=\theta^{*}}=0,\left.\frac{\partial^{2} \operatorname{Det} .\left(\sigma_{i j}\right)}{\partial \theta^{2}}\right|_{\theta=\theta^{2}}<0$

The ticklish stress for crack initiation is estimated by:

$\operatorname{Det} .\left(\sigma_{i j}\right)=\operatorname{Det} .\left(\sigma_{i j}\right)_{c r}$

\section{Cyclic Load Equations}

The equations below are available for transverse crack $\left(\alpha=90^{\circ}\right)$ with and without internal pulse pressure [6]

$p=w\left[1+\sqrt{\frac{1+2 h E A}{w l}}\right]$

$I=\frac{\pi}{64}\left(O D^{4}-I D^{4}\right)$

$\delta=\frac{l^{3} p}{48 E I} \quad$ (For simply supported)

$\sigma=\frac{\mathrm{MY}}{\mathrm{I}} \quad$ (Bending stress)

$\sigma_{\min }=-\sigma_{\max }$ 


$$
\begin{aligned}
& \beta=\frac{a_{j}}{r} \\
& \rho_{0}=\frac{a_{j}}{\sqrt{r t}} \\
& G_{2}\left(\rho_{0}\right)=1+0.19 \rho_{0}+0.01 \rho_{0}^{2} \\
& C_{1}=1+\frac{0.7071(1-\beta \cot (\beta))}{\left(\frac{\cot (\pi-\beta)}{\sqrt{2}}+\sqrt{2} \cot (\beta)\right) * \beta} \\
& C_{2}=1+\frac{0.35355\left(\beta+\beta \cot ^{2}(\beta)-\cot (\beta)\right)}{\left(\frac{\cot (\pi-\beta)}{\sqrt{2}}+\cot (\beta)\right)} \\
& C C F_{I}=\left(G_{2}\left(\rho_{0}\right) * \operatorname{Sin}(\beta) * C_{2}\right) /\left(\beta * C_{1}\right) \\
& K_{I}=\sigma_{\text {app }} \sqrt{\pi a_{j}} C C F_{I}=K_{\operatorname{Imax}}
\end{aligned} .
$$

\section{Material Used and Specimens}

The material used in this research is Low Carbon Steel (EN 10219 S235JRH). It is a pipe with a circular section thickness about $1.4 \mathrm{~mm}$ and a diameter about $75 \mathrm{~mm}$. This research was done on several samples of this article. Some of these samples have a length of $100 \mathrm{~cm}$ [7], See Fig. 1 and other have length of $50 \mathrm{~cm}$ See Fig. 2. The reason for this difference to test the effect of bending on the growth and behavior of the crack. This test was conducted under different environmental conditions to determine the effect of the moisture and heat factors on the growth of the crack.

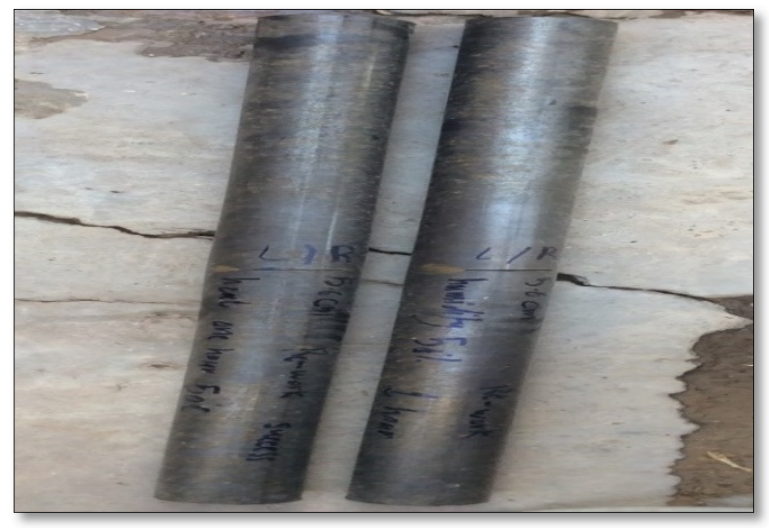

Fig.1. Two sample of length $100 \mathrm{~cm}$.

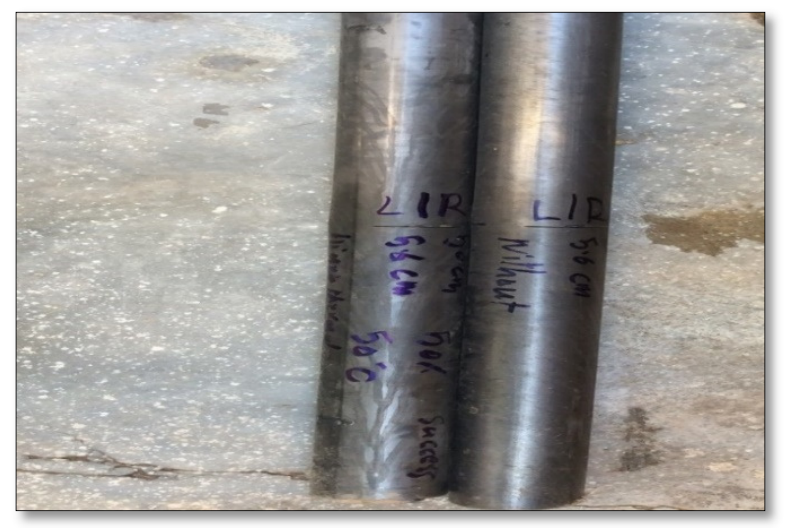

Fig. 2. Two sample of length $50 \mathrm{~cm}$.

\section{Manufacturing of The Rig}

This device was made of several parts of iron material with different sections according to the required part. Also used the technique of electric arc welding to connect these parts. The parts are cut using the cutting machine. After the cutting, the welding process is carried out to connect them together. However, most parts of this machine have the ability to switch when failure or damage occurs in one of these parts. The rig has the facility of making test for different length of pipes and different fixing conditions to match the requirement for the end fixing. A wooden plate was used to fix the parts of the machine. The dimensions of this plate are $(122 \mathrm{~cm} \mathrm{x} 244 \mathrm{~cm})$ and thickness $1.5 \mathrm{~cm}$. This plate has a hole in the middle to facilitate the passage of the hammer lever and to facilitate the examination of the pipe using the camera or naked eye. The dimensions of the parts of each other were developed using a laser device called (level) (see fig.3) that allows the device to see the extent of the separation of these parts or deviation from each other, which adds the possibility of placing the parts with high accuracy. This device enables the possibility of conducting tests on pipes made of iron, carbon steel, aluminum, copper and plastic. The design of this device includes the possibility of changing the height of the hammer to suit the amount of energy necessary and strong with the ability of the metal to withstand the shocks, Also can work on the pipes of different length ranging from $50 \mathrm{~cm}$ to $150 \mathrm{~cm}$ and different diameters ranging from 2 to 4 inch. In addition, the researcher or worker on this device can control the environmental conditions to be operated from heat, humidity, and control where it can work in the areas of temperature ranging from $0{ }^{\circ} \mathrm{C}$ to $100{ }^{\circ} \mathrm{C}$. Also, control the humidity, where it can work in the humidity ratio ranging from $0 \%$ to $100 \%$.

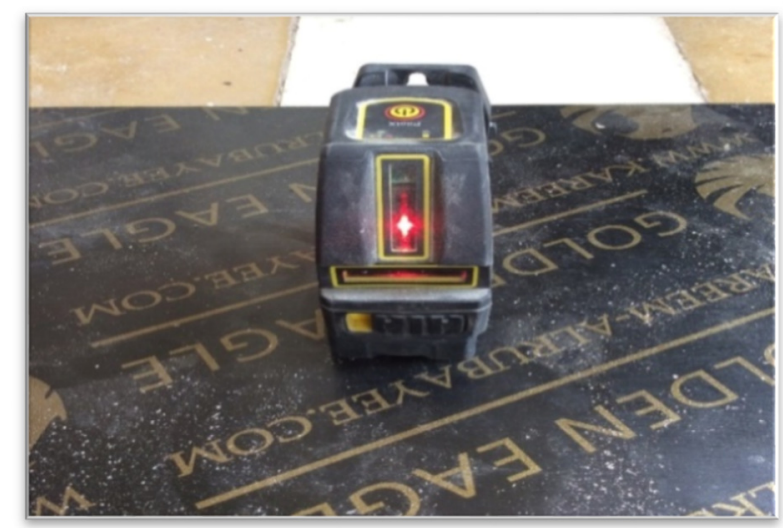

Fig. 3. level device. 


\section{Material Properties}

These properties from DIN EN 10219

1. Chemical composition

Chemical composition is in percentage by mass.

See Table 1.
2. Mechanical properties

These mechanical properties measured at room temperature, See Table 2

3. Physical properties.

Physical properties for this material shown in the Table 3.

Table 1,

Chemical properties of material

\begin{tabular}{|c|c|c|c|c|c|c|}
\hline Carbon $\mathrm{C}$ & Silicon & $\mathbf{S i}$ & Manganese Mg & Phosphorus P & Sulfur Ag & Nitrogen $N$ \\
\hline 0.17 & - & & 1.4 & 0.04 & 0.04 & 0.009 \\
\hline
\end{tabular}

Table 2,

Mechanical properties of material

\begin{tabular}{ll} 
Yield strength in $\mathrm{N} / \mathrm{mm}^{2}$ min for nominal wall thickness & 235 \\
Tensile strength in $\mathrm{N} / \mathrm{mm}^{2}$ for nominal wall thickness & $360-510$ \\
Elongation $\%$ for nominal wall thickness & 24 \\
Impact energy in $\mathrm{J}$ at temperature $20^{\circ} \mathrm{C}$ & 27 \\
\hline
\end{tabular}

Table 3,

Physical properties of material

\begin{tabular}{ll}
\hline Density at $20^{\circ} \mathrm{C}$ in $\mathrm{kg} / \mathrm{dm}^{3}$ & 7.85 \\
Modulus of elasticity kN/mm $/ \mathrm{mm}^{2}$ at $20^{\circ} \mathrm{C}$ & 210 \\
Thermal conductivity at $20^{\circ} \mathrm{C}$ in $\mathrm{W} / \mathrm{m} \mathrm{k}$ & 54 \\
Spec. thermal capacity at $20^{\circ} \mathrm{C} \mathrm{J} / \mathrm{kg} \mathrm{k}$ & 461 \\
Spec. electrical resistivity at $20^{\circ} \mathrm{C} \Omega \mathrm{mm}^{2} / \mathrm{m}$ & 0.15 \\
\hline
\end{tabular}

\section{Crack Initiation}

The crack was created manually by handsaw. Because that the crack is difficult to accomplish using other machines. Where the length of the cut about 24\% [8] of the perimeter of the pipe. This percentage was based on previous research, where the length was $56 \mathrm{~mm}$ and width of the crack is about $0.7 \mathrm{~mm}$ to $0.9 \mathrm{~mm}$. This difference is due to the difference in the thickness of the cutting edge in the saw as well as the hand movement. Other percentages were chosen to indicate the possibility of conducting the search on different lengths of the crack. However, these lengths of $(18 \mathrm{~mm}, 25 \mathrm{~mm}$, $30 \mathrm{~mm}$, and $40 \mathrm{~mm}$ ) took a long time without any continuity in the growth of the crack.

\section{Results and Calculations}

Table 4. and table 5. Show the calculations that must be used in this search, then use it in the governing equations, table 6 and table 7 . To ensure the regular work convicted by equations in point 5 . Results were obtained by using rig made for testing these specimens. See Fig. 4, the tests were repeated again to ensure a close test result as well as to ensure the correct functioning of the rig. The results are shown in the Fig. 8, Fig. 9, Fig. 10, and Fig. 11.

Outer diameter $(\mathrm{OD})=0.075 \mathrm{~m}$, inner diameter (ID) $=0.0722 \mathrm{~m}$, thickness $(\mathrm{t})=0.0014 \mathrm{~m}$ Yield point $=$ $235 \mathrm{Mpa}$, modules of elasticity $(\mathrm{E})=210 \mathrm{Gpa}$, high (h) $=0.57 \mathrm{~m}$, weight of hammer $(\mathrm{w})=6.7 \mathrm{Kg}$

Table 4,

Calculation for $100 \mathrm{~cm}$ specimens.

\begin{tabular}{|c|c|c|c|}
\hline $\begin{array}{l}\text { Effective length is } 1 \mathrm{~m} \\
\text { Load applied } \mathrm{N}\end{array}$ & Moment of inertia $m^{4}$ & Deflection $m$ & Bending stress Mpa \\
\hline 2279.3 & $0.22 * 10^{-6}$ & 0.0103 & 1949.1 \\
\hline
\end{tabular}

Table 5,

Calculations for $50 \mathrm{~cm}$ specimens

\begin{tabular}{|c|c|c|c|c|c|}
\hline $\begin{array}{l}\text { Effective length is } 0.5 \mathrm{~m} \\
\text { Load applied } \mathrm{N}\end{array}$ & Moment of inertia & $m^{4}$ & Deflection $m$ & Bending stress & Мра \\
\hline 2223.2 & $0.22 * 10^{-6}$ & & 0.0018 & 1378.1 & \\
\hline
\end{tabular}


Table 6,

Calculation using cyclic load equations for $100 \mathrm{~cm}$ specimens

\begin{tabular}{lllllll}
\hline $\begin{array}{l}\text { Type of test } \\
\text { without }\end{array}$ & $\mathbf{k 1}$ & & $\mathbf{k 2}$ & \multicolumn{3}{c}{ Slop $(\boldsymbol{m})$} \\
& LHS & RHS & LHS & RHS & LHS & RHS \\
\cline { 2 - 7 } hygrothermal & $1.8 * 10^{8}$ & $1.8 * 10^{8}$ & $1.87 * 10^{8}$ & $1.87 * 10^{8}$ & 6.91 & 8.4 \\
\hline
\end{tabular}

Table 7,

Calculation using cyclic load equations for $50 \mathrm{~cm}$ specimens

\begin{tabular}{|c|c|c|c|c|c|c|}
\hline \multirow{2}{*}{$\begin{array}{l}\text { Type of test } \\
\text { without }\end{array}$} & \multicolumn{2}{|c|}{ k1 } & \multicolumn{2}{|c|}{ k2 } & \multicolumn{2}{|c|}{ Slop (m) } \\
\hline & LHS & RHS & LHS & RHS & LHS & RHS \\
\hline & $1.33 * 10^{8}$ & $1.33 * 10^{8}$ & $1.35^{*} 10^{8}$ & $1.35 * 10^{8}$ & 2 & 7.6 \\
\hline hygrothermal & $9.22 * 10^{8}$ & $9.5^{*} 10^{8}$ & $9.28 * 10^{8}$ & $9.7 * 10^{8}$ & 3.9 & 7 \\
\hline
\end{tabular}

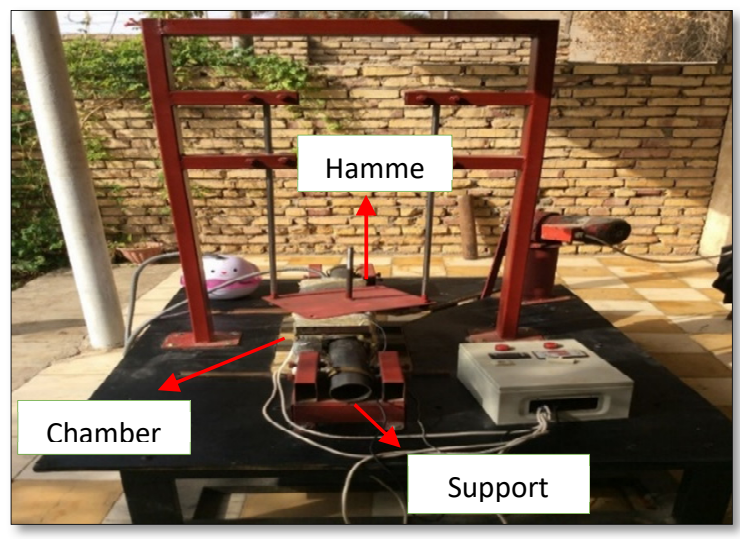

Fig. 4. The rig used in this research.

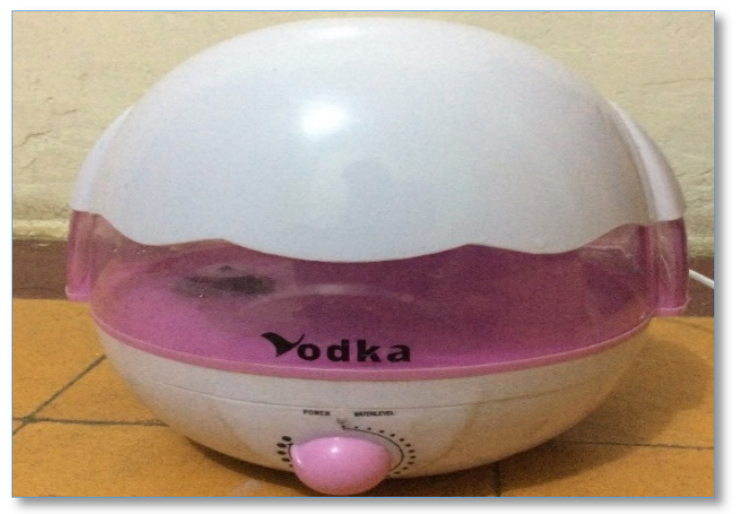

Fig. 5. Humidifier device.

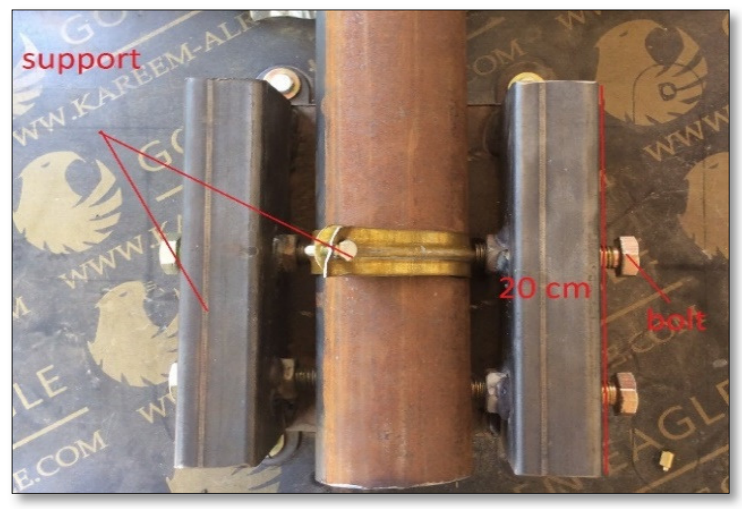

Fig. 6. Support.

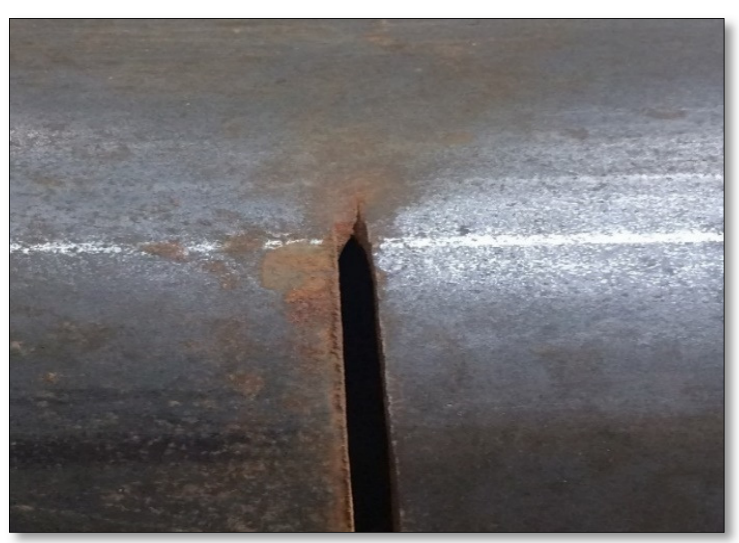

Fig.7. Close up photo show the crack and crack growth.

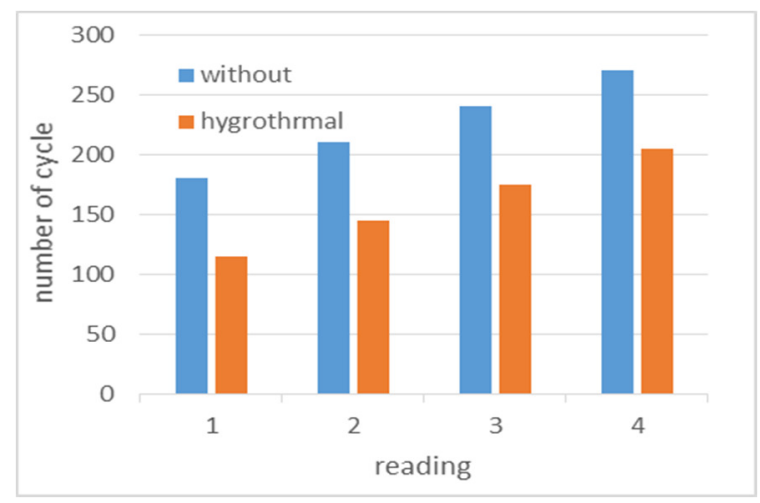

Fig. 8. Show number of cycle of $100 \mathrm{~cm}$ specimens.

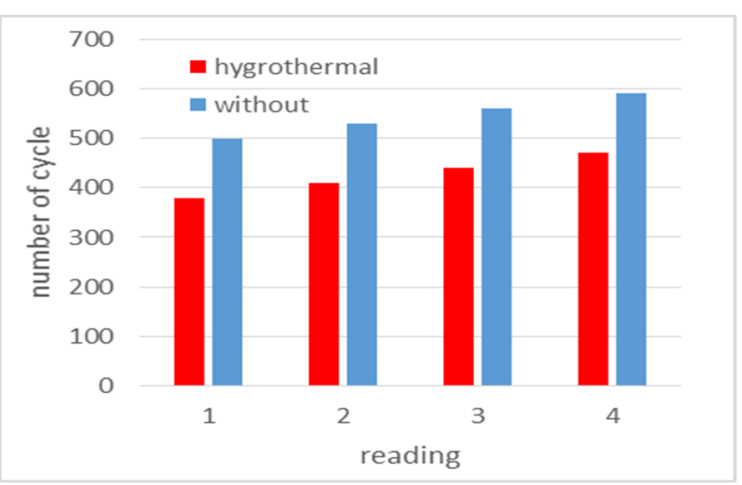

Fig. 9. Show number of cycle of $50 \mathrm{~cm}$ specimen. 


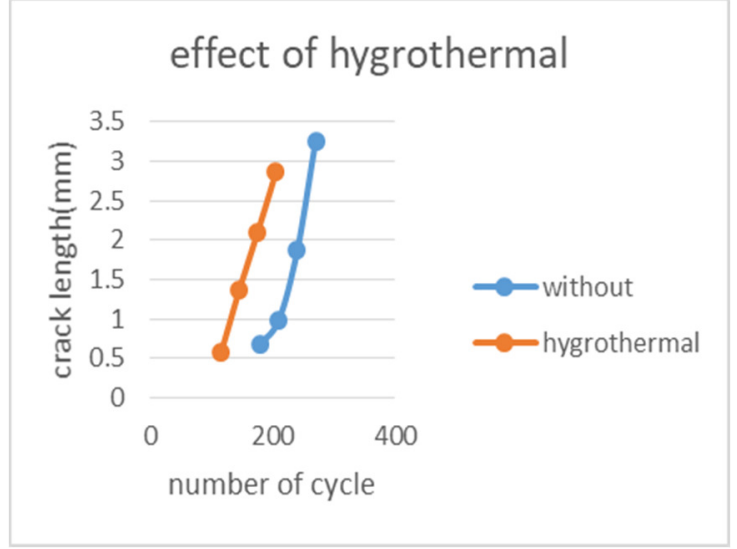

Fig. 10. Effect of hygrothermal on crack growth for $100 \mathrm{~cm}$ specimens.

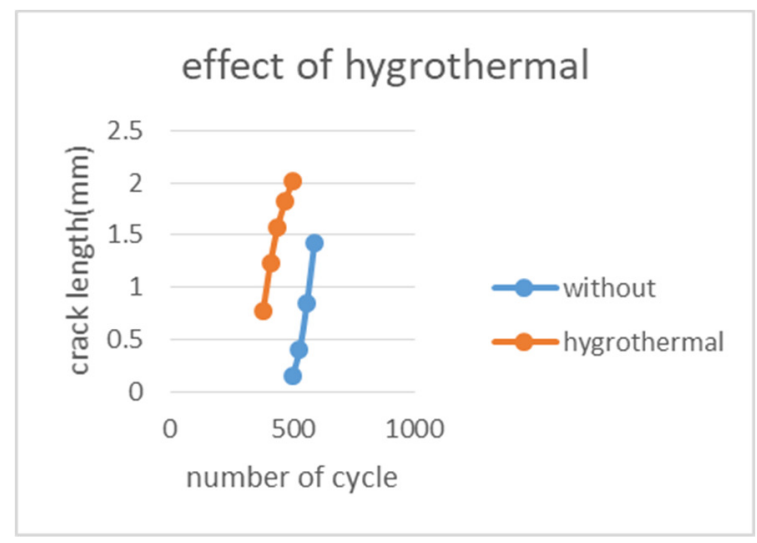

Fig.11. Effect of hygrothermal on crack growth for $50 \mathrm{~cm}$ specimens.

\section{Conclusion}

The purpose of this study is to determine the extent to which the crack is able to grow when shedding and how long it takes to grow these cracks. Some things need to be discussed to know what changes are made to these cracks and to make things better.

1- The number of cycle needed to growth the crack are reduced due to the effect of humidity because the formation of oxides on the fracture surface.

2- The number of cycle needed to growth the crack in the specimens of length $50 \mathrm{~cm}$ are increase because the effect of bending stress in the pipes.

3- The number of cycles needed to growth the crack are reduced because the effect of heat on the mechanical properties of the material that helps to increase the ductility.

\section{Notations}

$\begin{array}{ll}\text { LEFM } & \text { linear elastic fracture mechanics } \\ \text { MTS } & \text { multi-tasking staff } \\ \mathrm{da} / \mathrm{dN} & \text { crack growth per cycle, } \mathrm{m} / \text { cycle } \\ \mathrm{r}, \theta & \text { polar coordinate, dimensionless } \\ \mathrm{k}_{1}, \mathrm{k}_{2} & \text { stress intensity factor, Mpa } \sqrt{m} \\ E & \text { young modulus, Gpa }\end{array}$

\section{Greek Letters}

$\begin{array}{ll}\pi & \text { mathematical constant, } \\ v & \text { dimensionless } \\ \delta & \text { poison ratio, dimensionless } \\ \theta & \text { deflection, } \mathrm{m} \\ \tau_{r \theta} & \begin{array}{l}\text { angle of crack propagation, degree } \\ \text { shear stress in cylindrical }\end{array} \\ \sigma_{x}, \sigma_{y} & \text { coordinate, Mpa } \\ , \tau_{x y} & \text { component of stress tensor, Mpa } \\ \sigma_{\theta} & \text { circumferential stress near crack } \\ \beta & \text { tip, Mpa } \\ & \text { non dimensional factor, unit less }\end{array}$

\section{References}

[1]Bertram Broberg, K., 1999, Cracks and Fracture Academic press, pages 1-4, ISBN: 978-0-12-134130-5

[2]Stein, D., 2004, Rehabilitation and Maintenance of Drains and Sewers, technique technology center

[3]Mcevily, A. J, 1996, The Growth of Short Fatigue Crack, Transaction of material science, Vol. 13, pages 1-5

[4]Forman, R. G., Kearney, V. E., Engle, R. M., 1967, Numerical Analysis of Crack Propagation in Cyclic Loaded Structures, pages 459-463

[5]Wasiluk, B., Golos, K., 2000, Prediction of Crack Growth Direction under Plane Stress for Mixed Mode I and II Loading, pages 6

[6]Al Laham S., Ainsworth R. A.,1999, Stress Intensity Factor and Limit Load Handbook, British Energy Generation Ltd., UK

[7]Anil, O., Erdem, R. T., Kantar, E., 2015, Improving the Impact Behavior of Pipes Using Geofoam Layer for Protection, International Journal of Pressure vessel and piping, pages 52-64

[8]G. M. Wilkowski, Gadiali, N., Rudland, D., Krishanswamy, P., Rahman, S., Scott, P., 1994, Short Cracks in Piping and Pipe Welds, Vol 4, no 1, pages 78 


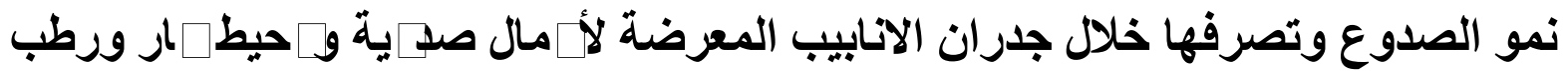

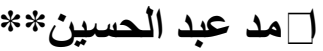

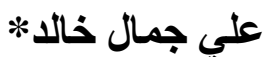

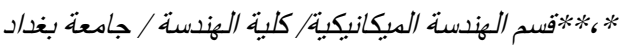 \\ engalijama193@gmail.com البريد الإلكترونية \\ ahmedrobot65@yahoo.com البريد الالكتروني: (البرني: 2**
}

الخلاصة

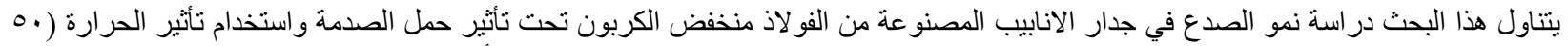

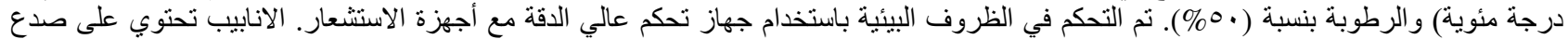

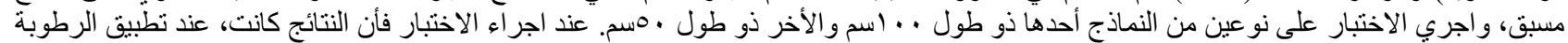

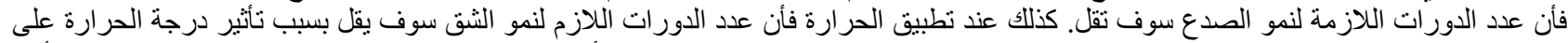

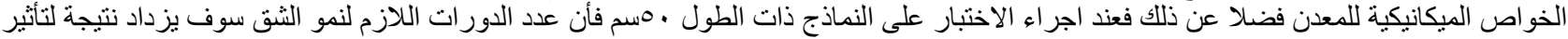

